\title{
Deployment-related mental disorders among Canadian Forces personnel deployed in support of the mission in Afghanistan, 2001-2008
}

\author{
David Boulos MSc, Mark A. Zamorski MD MHSA
}

\begin{abstract}
Background: The conflict in Afghanistan has exposed more Canadian Forces personnel to a greater degree of adversity than at any time in recent memory. We determined the incidence of Afghanistan deployment-related mental disorders and associated risk factors among personnel previously deployed in support of this mission.
\end{abstract}

Methods: The study population consisted of 30513 Canadian Forces personnel who began a deployment in support of the mission in Afghanistan before Jan. 1, 2009. The primary outcome was a mental disorder perceived by a Canadian Forces clinician to be related to the Afghanistan deployment. Data on diagnoses and perceptions were abstracted from medical records of a stratified random sample of 2014 personnel. Sample design weights were used in all analyses to generate descriptive statistics for the entire study population.

Results: Over a median follow-up of 1364 days, $13.5 \%$ (95\% confidence interval [CI]
$12.1 \%-14.8 \%$ ) of the study population had a mental disorder that was attributed to the Afghanistan deployment. Posttraumatic stress disorder was the most common diagnosis (in $8.0 \%, 95 \% \mathrm{Cl} 7.0 \%-9.0 \%$, of personnel). Deployment to higher-threat locations, service in the Canadian Army and lower rank were independent risk factors associated with an Afghanistan-related diagnosis (e.g., hazard ratio for deployment to Kandahar Province 5.6, 95\% Cl 2.6-12.5, relative to deployment to the United Arab Emirates). In contrast, sex, Reserve Forces status, multiple deployments and deployment length were not independent risk factors.

Interpretation: An important minority of Canadian Forces personnel deployed in support of the Afghanistan mission had a diagnosis of a mental disorder perceived to be related to the deployment. Determining long-term outcomes is an important next step.
Competing interests: None declared.

This article has been peer reviewed.

Correspondence to: David Boulos, david.boulos @ forces.gc.ca

CMAJ 2013. DOI:10.1503 /cmaj.122120
$\mathrm{M}$ ore than 40000 Canadian Forces personnel have been deployed in support of the mission in Afghanistan from its inception in 2001 to December 2012. Data from Canada's closest allies ${ }^{1-7}$ have shown that an important minority of their personnel deployed to the conflicts in Southwest Asia have mental health problems, many apparently related to their deployment. Mental disorders have important implications for military and veteran organizations and are leading causes of impaired productivity, ${ }^{8}$ absenteeism ${ }^{8}$ and turnover. ${ }^{2,9}$ In addition, the unusual demands of military work are such that impairment in functioning due to mental health problems can threaten the safety and success of military operations. ${ }^{10}$ Moreover, mental health care represents a large and growing proportion of all health services delivered by military organizations. ${ }^{11-13}$ Finally, service-related mental health problems are an important driver of benefits and services for veterans. ${ }^{14}$
Although research findings from other nations involved in the conflicts in Southwest Asia are informative, each nation differs in important ways, including the characteristics of military personnel, their experiences while deployed and their unique military culture. Each nation also differs in the way it delivers mental health services. The Canadian Forces has invested heavily in its mental health care system over the past decade, with the following key enhancements: doubling the number of civilian and military mental health care personnel; strengthening mental health screening, particularly following deployment; implementing 7 regional centres for the assessment and treatment of service-related mental health problems; strengthening medical confidentiality protections; and requiring extensive mental health and resilience training over the course of the deployment and career cycle.

Canadian data on the psychological impact of the mission in Afghanistan were largely limited 
to survey data collected during mental health screening done about 6 months after return from deployment and limited to those deployed since 2006. ${ }^{15}$ About 5\% reported significant symptoms of posttraumatic stress disorder (PTSD) or depression at screening. ${ }^{15}$ However, the proportion formally diagnosed with a deploymentrelated mental disorder for the mission as a whole is unknown.

We conducted this study to deepen the understanding of the impact of the Afghanistan mission on Canadian Forces personnel, expanding on preliminary results reported earlier. ${ }^{16}$ We determined the incidence of diagnosed mental disorders among personnel deployed in support of the Afghanistan mission that were perceived to be related to the deployment. We also identified key military and demographic risk factors associated with the diagnoses.

\section{Methods}

\section{Setting}

The deployment of Canadian Forces personnel from 2001 to 2008 to various locations in support of the mission in Afghanistan is outlined in Table 1. Land Forces focused on combat and peace support operations in Kabul (2003-2005) and Kandahar Province (2002 and 2005-2011), where nearly all of the more than 150 deaths of Canadian Forces personnel have occurred. Maritime Forces deployed numerous major vessels in and around the Arabian Gulf from 2001 to 2008; roles included force protection, fleet support and maritime interdiction. Air Forces contributed strategic and tactical airlift support and long-range patrol and surveillance capabilities over the full duration of the mission; most Air Force personnel were stationed in the United Arab Emirates.

\section{Study population}

The study cohort consisted of all Canadian Forces personnel who began a deployment outside of North America or Europe in support of the mission in Afghanistan from Oct. 1, 2001, through Dec. 31, $2008(n=30$ 513).

We identified a weighted, stratified, random sample of 2045 individuals for review of their medical records. The strata were defined by location of deployment (6 categories) and apparent use and nonuse of Canadian Forces mental health services ( 2 categories), for a total of 12 strata. Identified weights were used in the analyses. The deployment locations were Kandahar Province; Kabul or elsewhere in Afghanistan; the United Arab Emirates or elsewhere in the Middle East; the Arabian Gulf (on board ship); multiple locations; and unspecified location (deployment was in support of the mission in Afghanistan, but information on the specific location was not available in the database). We determined apparent use and nonuse of mental health services using data from the Canadian Forces Health Information System and appointment scheduling systems, as well as claims data for outsourced care.

The study was powered to achieve a precision of $\pm 1 \%$ around a cumulative incidence point estimate of $8 \%$. Sample size per stratum was determined using the Neymann optimal allocation approach. ${ }^{17}$

\begin{tabular}{|c|c|c|c|c|c|c|c|}
\hline \multirow{3}{*}{$\begin{array}{l}\text { Year } \\
2001\end{array}$} & \multicolumn{7}{|c|}{ Location*; no. of personnel (no. of person-yearst) } \\
\hline & Kandahar & \multicolumn{2}{|c|}{ Kabul } & United Arab Emirates & Arabian Gulf & Multiple locations $\ddagger$ & Unspecified \\
\hline & $(0.0)$ & 0 & $(0.0)$ & (8.1) & $1448 \quad(171.3)$ & $(12.7)$ & $15 \quad(0.8)$ \\
\hline 2002 & $615 \quad(240.1)$ & 1 & $(0.1)$ & $907 \quad(322.3)$ & $2930 \quad(711.5)$ & $647 \quad(223.1)$ & $157(58.3)$ \\
\hline 2003 & $(0.0)$ & 1261 & $(438.0)$ & $916 \quad(225.1)$ & $1294 \quad(326.5)$ & $1809 \quad(592.7)$ & $29 \quad(2.6)$ \\
\hline 2004 & $(0.0)$ & 2702 & $(757.4)$ & $545 \quad(102.4)$ & $(31.7)$ & $2504 \quad(646.4)$ & $60 \quad(6.9)$ \\
\hline 2005 & $518 \quad(139.4)$ & 1251 & (354.9) & (62.7) & $(52.5)$ & $1670 \quad(450.6)$ & $41 \quad(3.8)$ \\
\hline 2006 & $3754(1427.8)$ & 410 & $(70.9)$ & $507 \quad(133.0)$ & $(60.0)$ & $1652 \quad(542.5)$ & $132(15.9)$ \\
\hline 2007 & $5658(1986.2)$ & 168 & $(56.0)$ & $537 \quad(129.1)$ & $(64.4)$ & $2085 \quad(656.7)$ & 134 (19.7) \\
\hline 2008 & 7055 (2 358.9) & 132 & $(44.7)$ & $533 \quad(115.9)$ & 1057 & $2034 \quad(588.6)$ & 111 (19.2) \\
\hline Overall§ & 12745 (6 152.4) & 4144 & $1721.9)$ & 3125 (1 098.7) & 5260 (1 769.6) & 4655 (3 713.4) & $584(127.2)$ \\
\hline \multicolumn{8}{|c|}{$\begin{array}{l}\text { *See Methods for details about deployment locations. } \\
\text { tPerson-years are lower than the number deployed because standard deployments typically lasted } 6 \text { months and others were for shorter or longer terms. } \\
\text { fPersonnel in this category are not included in the other, single-location categories. } \\
\text { §The sum of the numbers of personnel for each location is greater than the overall number because personnel may have been deployed more than once to the } \\
\text { same location or had a deployment that spanned } 2 \text { or more years over the study period. }\end{array}$} \\
\hline
\end{tabular}




\section{Data collection}

We obtained data on the deployment location, departure and return dates, and military and demographic covariates by linking and crossvalidating data from the Canadian Forces computerized human resources, tasking and pay systems. Age, military rank and component (i.e., Regular Forces or Reserve Forces) were determined with respect to the start date of individuals' first Afghanistan-related deployment.

\section{Outcome measure}

The primary outcome was the presence of a deployment-related mental disorder. Such disorders had to meet DSM-IV-TR (Diagnostic and Statistical Manual of Mental Disorders, fourth edition, text revision) criteria $^{18}$ and be judged by the clinician doing the assessment to be at least partially related to a deployment in support of the mission in Afghanistan.

Evaluation of service-related mental disorders is done in 1 of 7 Canadian Forces regional mental health centres. The evaluations follow a common, collaborative assessment model that includes psychological testing and consultation with (at minimum) a psychiatrist and a psychologist. ${ }^{16}$ The evaluation process lasts at least 4 hours. The clinicians comment on the association between the diagnosis and military service because this can have implications in terms of veterans' benefits.

Data on DSM-IV diagnosis ${ }^{18}$ and the clinician's perception of the relationship of the diagnoses to the Afghanistan operation were abstracted from Canadian Forces medical records by one of 2 experienced research nurses.

\section{Statistical analysis}

The data were analyzed using SAS for Windows, version 9.3 (SAS Institute Inc.). We used the Taylor series linearization method ${ }^{19}$ with sample design weights to determine $95 \%$ confidence intervals (CIs) for descriptive statistics except for incidence density estimates, for which we used bootstrap methods. ${ }^{20,21}$ Two-sample $\mathrm{Z}$ tests were used to compare differences in incidence density between variable levels, with Bonferroni-corrected significance set at $p$ less than 0.05 .22

We used weighted Kaplan-Meier curves $^{23}$ to generate event probabilities that were representative of the cohort. Zero time was defined as the return date after the first Afghanistan-related deployment. Event date was specified as the date of the diagnosed mental disorder; personnel were censored at their military release date or date of chart review, whichever was earlier. United Arab Emirates and Arabian Gulf locations were combined for ease of interpretation, because there
Table 2: Demographic and military characteristics of the study cohort ( $n=30$ 513) and the chart-review sample $(n=2014)$

Group; no. (\%) of personnel

\begin{tabular}{|c|c|c|c|}
\hline \multirow[b]{2}{*}{ Characteristic } & \multicolumn{3}{|c|}{ Group; no. (\%) of personnel } \\
\hline & Study cohort & $\begin{array}{c}\text { Chart-review } \\
\text { sample }\end{array}$ & $\begin{array}{l}\text { Weighted } \\
\text { estimate* }\end{array}$ \\
\hline
\end{tabular}

\begin{tabular}{|lrrr|}
\hline Sex & & & \\
\hline Male & $27538(90)$ & $1772(88)$ & $27625(91)$ \\
\hline Female & $2971(10)$ & $242(12)$ & $2888(9)$ \\
\hline Unspecified & $4(<0.5)$ & 0 & 0 \\
\hline Age, yr & & & \\
$<30$ & $12282(40)$ & $748(37)$ & $11395(37)$ \\
\hline $30-39$ & $11531(38)$ & $803(40)$ & $12014(39)$ \\
$\geq 40$ & $6695(22)$ & $463(23)$ & $7104(23)$
\end{tabular}

\begin{tabular}{lccc|} 
Component & & & \\
\hline Regular Forces & $27282(89)$ & $1870(93)$ & $27831(91)$ \\
Reserve Forces & $3227(11)$ & $144(7)$ & $2682(9)$ \\
Unspecified & $4(<0.5)$ & 0 & 0
\end{tabular}

Element

\begin{tabular}{|lrcr}
\hline Land & $19634(64)$ & $1419(70)$ & $19278(63)$ \\
\hline Sea & $5340(18)$ & $223(11)$ & $5173(17)$ \\
\hline Air & $5531(18)$ & $372(18)$ & $6063(20)$ \\
\hline Unspecified & $8(<0.5)$ & 0 & 0 \\
\hline Rank & & & \\
\hline Officer & $4902(16)$ & $308(15)$ & $4843(16)$ \\
\hline Senior NCM & $5471(18)$ & $369(18)$ & $5478(18)$ \\
\hline Junior NCM & $20131(66)$ & $1337(66)$ & $20193(66)$ \\
\hline Unspecified & $9(<0.5)$ & 0 & 0 \\
\hline Location of deployment & & & \\
\hline Kandahar & $12745(42)$ & $865(43)$ & $12745(42)$ \\
\hline Kabul & $4144(14)$ & $320(16)$ & $4144(14)$ \\
\hline United Arab Emirates & $3125(10)$ & $119(6)$ & $3125(10)$ \\
\hline Arabian Gulf & $5260(17)$ & $148(7)$ & $5260(17)$ \\
\hline Multiple locations & $4655(15)$ & $413(21)$ & $4655(15)$ \\
\hline Unspecified & $584(2)$ & $149(7)$ & $584(2)$ \\
\hline No. of deployments & & & \\
\hline 1 & $24427(80)$ & $1547(77)$ & $24565(81)$ \\
\hline 2 & $5155(17)$ & $385(19)$ & $4911(16)$ \\
\hline$\geq 3$ & $931(3)$ & $82(4)$ & $1037(3)$
\end{tabular}

\begin{tabular}{|lrrr|}
\hline $\begin{array}{l}\text { Duration of first } \\
\text { deployment, d }\end{array}$ & & & \\
\hline$<180$ & $18150(59)$ & $1199(60)$ & $18282(60)$ \\
\hline $180-365$ & $12103(40)$ & $792(39)$ & $11971(39)$ \\
\hline$>365$ & $260(1)$ & $23(1)$ & $260(1)$ \\
\hline $\begin{array}{l}\text { Total duration of } \\
\text { deployments, d }\end{array}$ & & & \\
\hline$<180$ & $14827(49)$ & $936(47)$ & $15010(49)$ \\
\hline $180-365$ & $13831(45)$ & $910(45)$ & $13520(44)$ \\
\hline$>365$ & $1855(6)$ & $168(8)$ & $1984(6.5)$ \\
\hline
\end{tabular}

Note: deployment = deployment in support of Afghanistan mission, NCM = noncommissioned officer.

*Sample design weights were used to compute descriptive statistics that were representative of the entire study population. 
was no significant difference in incidence density or hazard ratios for these locations in the univariable analyses. In a weighted Cox regression model, we analyzed the association of Afghanistan deployment-related mental disorder diagnoses with covariates chosen for assessment using the Akaike information criterion and a forward variable selection process. ${ }^{23}$

\section{Ethical aspects}

The research protocol was approved by Veritas Research Ethics Board.

\section{Results}

We were able to review the medical records for 2014 (98.5\%) of the 2045 individuals in the random sample. The records of the other 31 individuals were not accessible before the end of the chart-review phase, either because they were in transition to a new location or were in active use for reasons other than treatment.

The study cohort consisted largely of men under the age of 40 in the Regular Forces (Table 2). Although deployments to Kandahar Province predominated, there was good representation for all deployment locations. Individuals in the "multiple locations" category had primarily Kabul (81\%) and Kandahar Province $(75 \%)$ in their location mix, usually in that temporal sequence. Deployment location was not specified precisely but was identified as being in support of the Afghanistan mission for $2 \%$ of the cohort. Key variables were missing for less than $0.5 \%$ of the full cohort and were complete for the entire chart-review sample.

Overall, $29.6 \%$ (95\% CI $27.7 \%-31.6 \%$ ) of the study population used Canadian Forces mental health services over a median follow-up of 1364 days (mean $1525 \mathrm{~d}$; range 1-3344 d) from the return date after the first Afghanistan-related deployment to the earlier of the event or censor date. The median follow-up was shortest for personnel deployed to Kandahar (892 d) and longest for those deployed to the Arabian Gulf (2551 d) and multiple locations (2202 d).

An estimated $13.5 \%$ of the study cohort had a mental disorder attributed to the Afghanistan mission (Table 3). Most of these personnel (78.5\%, or $10.6 \%$ [ $95 \%$ CI $9.4 \%-11.9 \%$ ] of the whole cohort) were judged by a clinician to have a diagnosis largely related to the mission. The most common Afghanistan-related disorder was PTSD $(8.0 \%)$, followed by depressive disorders $(6.3 \%$, $60.3 \%$ [1158/1919] of which were comorbid with PTSD). An additional 5.5\% (95\% CI 4.5\%$6.6 \%$ ) of the cohort had a mental disorder judged to be unrelated to their Afghanistan deployment; this group included the $1.2 \%$ (95\% CI $0.7 \%-$ $1.7 \%$ ) of the cohort who had a mental disorder related to other Canadian Forces operations.

Incidence densities of Afghanistan-related mental disorders were significantly associated with deployment location, age, rank, element

Table 3: Weighted cumulative incidence of all mental disorders diagnosed in the study cohort and of the subset of diagnoses attributed at least partially to Afghanistan-related deployments

\begin{tabular}{|c|c|c|c|c|}
\hline \multirow[b]{3}{*}{ Disorder } & \multicolumn{4}{|c|}{ Weighted* cumulative incidence of diagnosest } \\
\hline & \multicolumn{2}{|r|}{ Overall } & \multicolumn{2}{|c|}{$\begin{array}{c}\text { Attributed to } \\
\text { Afghanistan mission }\end{array}$} \\
\hline & No. & $\%(95 \% \mathrm{Cl})$ & No. & $\%(95 \% \mathrm{Cl})$ \\
\hline PTSD & 2703 & $8.9(7.8-9.9)$ & 2436 & $8.0 \quad(7.0-9.0)$ \\
\hline Other anxiety disorder & 1486 & $4.9(4.0-5.8)$ & 987 & $3.2(2.5-3.9)$ \\
\hline Any anxiety disorder & 3738 & $12.3(11.0-13.5)$ & 3012 & $9.9 \quad(8.8-11.0)$ \\
\hline Depressive disorder & 2553 & $8.4 \quad(7.2-9.5)$ & 1919 & $6.3(5.3-7.3)$ \\
\hline Bipolar disorder & 90 & $0.3 \quad(0.04-0.6)$ & 34 & $0.1 \quad(0-0.2)$ \\
\hline Other mood disorder & 97 & $0.3 \quad(0.07-0.6)$ & 81 & $0.3 \quad(0.03-0.5)$ \\
\hline Any mood disorder & 2698 & $8.8 \quad(7.7-10.0)$ & 1992 & $6.5(5.5-7.6)$ \\
\hline Adjustment disorder & 1408 & $4.6 \quad(3.8-5.4)$ & 913 & $3.0(2.4-3.6)$ \\
\hline Somatoform disorder & 102 & $0.3 \quad(0.1-0.6)$ & 16 & $0.1 \quad(0-0.1)$ \\
\hline Substance-related disorder & 975 & $3.2(2.4-4.0)$ & 599 & $2.0 \quad(1.5-2.4)$ \\
\hline Any of the above disorders & 5798 & $19.0(17.4-20.6)$ & 4108 & $13.5(12.1-14.8)$ \\
\hline \multicolumn{5}{|c|}{$\begin{array}{l}\text { Note: } \mathrm{Cl}=\text { confidence interval, } \mathrm{PTSD}=\text { posttraumatic stress disorder. } \\
\text { *Sample design weights were used to compute the cumulative incidence estimates and associated } 95 \% \text { Cls for the entire study } \\
\text { population. } \\
\text { †Many individuals had more than } 1 \text { diagnosed mental disorder. }\end{array}$} \\
\hline
\end{tabular}


(land, air or sea) and number of Afghanistanrelated deployments (Table 4). No statistically significant associations were noted with sex, component (Regular or Reserve Forces) or total duration of all deployments.

The "overall" Kaplan-Meier curve in Figure 1 shows that the probability of a mental disorder attributed to the Afghanistan mission started to plateau after 6 or more years of follow-up, with a cumulative incidence approaching $20 \%$ by the end of the follow-up period. The Kandahar location was associated with the highest probability of an Afghanistan deployment-related mental disorder over time (Figure 1). The probability was also higher for the Kabul and the "multiple locations" categories. Kaplan-Meier curves for rank and element showed an increased risk of Afghanistan-related mental disorders among personnel in Land Forces and junior noncommissioned personnel (data not shown).

Cox regression analysis showed that deployment location, rank and element were independently associated with the risk of an Afghanistan deployment-related mental disorder (Table 5). Deployment to Kandahar was associated with a particularly increased risk: it was almost 6 times the risk associated with deployment to the United Arab Emirates or Arabian Gulf and 2 times the risk associated with deployment to multiple locations or Kabul. Junior noncommissioned personnel were 1.7 times more likely than officers to have a diagnosis attributed to the Afghanistan mission; the same was true for personnel in the Land Forces compared with Air Forces personnel. Visual inspection of regression diagnostic plots was reassuring with respect to the proportional hazards assumption for every deployment location except the "multiple location" category. This latter category included a fairly large fraction of individuals with exposure to at least one of the Kandahar or Kabul locations and with relatively length follow-up. ${ }^{23}$

\section{Interpretation}

A sizable proportion (29.6\%) of the study population deployed in support of the Afghanistan mission used Canadian Forces mental health services during the follow-up period. Of these, an important minority (13.5\%) had a mental disorder perceived by a clinician to be related to the deployment. The most common of the disorders was PTSD. The overall probability of an Afghanistanrelated mental disorder started to plateau after 6 or more years of follow-up, with a cumulative incidence that approached $20 \%$ by the end of the follow-up period. The probability was highest among personnel deployed to Kandahar.
Table 4: Weighted incidence densities of mental disorders attributed at least partially to the Afghanistan mission, by demographic and military characteristics

\begin{tabular}{|c|c|}
\hline Characteristic* & $\begin{array}{l}\text { Weightedt incidence density, } \\
\text { no. per } 1000 \text { person-years }(95 \% \mathrm{Cl})\end{array}$ \\
\hline
\end{tabular}

\section{Sex}

Male $31.8(28.0-35.9)$

\section{Female}

$39.6(27.4-53.9)$

\section{Age, yrғ}

$\begin{array}{ll}<30 & 40.3(32.9-48.0) \\ 30-39 & 28.9(23.8-34.6) \\ \geq 40 & 27.7(20.0-37.0)\end{array}$

\section{Component}

Regular Forces

$31.9(28.1-35.7)$

Reserve Forces

$39.8(22.2-62.6)$

\section{Element§}

\begin{tabular}{ll} 
Land & $44.2(38.6-50.5)$ \\
\hline Sea & $18.5(11.4-27.5)$ \\
\hline Air & $15.7(10.5-21.8)$
\end{tabular}

\section{Rankף}

Officer

$21.4(13.6-30.6)$

Senior NCM

$31.5(23.2-41.0)$

Junior NCM

$35.4(30.5-40.5)$

Deployment location* *

\begin{tabular}{|rr}
\hline Kandahar & $65.5(55.6-76.2)$ \\
\hline Kabul & $29.3(22.2-38.0)$ \\
\hline United Arab Emirates & $8.6 \quad(3.2-14.9)$ \\
\hline Arabian Gulf & $14.6 \quad(7.6-23.3)$ \\
\hline Multiple locations & $26.9(21.6-32.8)$ \\
\hline Unspecified & $19.2(12.1-28.4)$ \\
\hline No. of deploymentstt & \\
\hline 1 & $34.0(29.2-39.0)$ \\
\hline 2 & $31.3(24.3-39.7)$ \\
\hline$\geq 3$ & $17.0(9.4-26.5)$ \\
\hline
\end{tabular}

Duration of first deployment, $d$

\begin{tabular}{|ll|}
\hline$<180$ & $28.7(24.4-33.4)$ \\
\hline $180-365$ & $40.8(33.4-48.6)$ \\
\hline$>365$ & $17.0(0.0-48.5)$ \\
\hline Total duration of all deployments, d & \\
\hline$<180$ & $29.0(23.7-34.5)$ \\
\hline $180-365$ & $38.3(31.9-45.2)$ \\
\hline$>365$ & $25.9(17.8-36.3)$ \\
\hline Overall & $32.5(28.8-36.5)$ \\
\hline
\end{tabular}

Note: $\mathrm{Cl}=$ confidence interval, deployment = deployment in support of Afghanistan mission, $\mathrm{NCM}=$ noncommissioned officer.

*Two-sample $Z$ tests were used to compare differences in incidence density between variable levels; significance set at $p<0.05$ after Bonferroni correction.

tSample design weights and bootstrap methods were used to compute the incidence density estimates and associated $95 \% \mathrm{Cls}$ for the entire study population.

$\ddagger p<0.05$ for difference between groups aged $<30$ and 30-39 yr.

$\S p<0.05$ for differences between Land and Sea Forces and between Land and Air Forces. १ $p<0.05$ for difference between officers and junior NCM ranks.

${ }_{* *} p<0.05$ for differences between Kandahar and each of the other locations, between Kabul and United Arab Emirates, and between "multiple locations" category and United Arab Emirates. $t+p<0.05$ for differences between $\geq 3$ deployments and 1 deployment, and between $\geq 3$ deployments and 2 deployments. 
Deployment to higher-threat locations, service in the Canadian Army and lower rank were independent risk factors associated with an Afghanistan-related mental disorder. In contrast, no independent association was seen with sex, Reserve Forces status, multiple deployments or deployment length. However, power to detect small differences was limited.

Because of methodologic differences, we were unable to directly compare our results with more widely available prevalence data from surveys. For example, in a 2002 survey, the 12month prevalence of PTSD in the Regular Forces was 2.8 and the lifetime prevalence $7.3 \% .{ }^{24,25}$ The structure of that survey prevented attribution of individual cases of PTSD or other mental disorders to a deployment, and those data predate both the Afghanistan conflict and the renewal of the Canadian Forces mental health services.

Data from postdeployment screenings showed that about $5 \%$ of personnel who returned from Afghanistan-related deployments since late 2005 had symptoms of PTSD or depression, or both, 6 months after their return; in most cases, the disorders were judged to be related to the most recent deployment. ${ }^{15}$ Anonymous survey data collected during 2008/09 from recently deployed personnel showed that about $8 \%$ screened positive for symptoms of PTSD with the use of a 4item screening tool. ${ }^{26}$ However, not all of those who screened positive at the cut-off used would have received a diagnosis of PTSD,${ }^{27}$ and the sur-

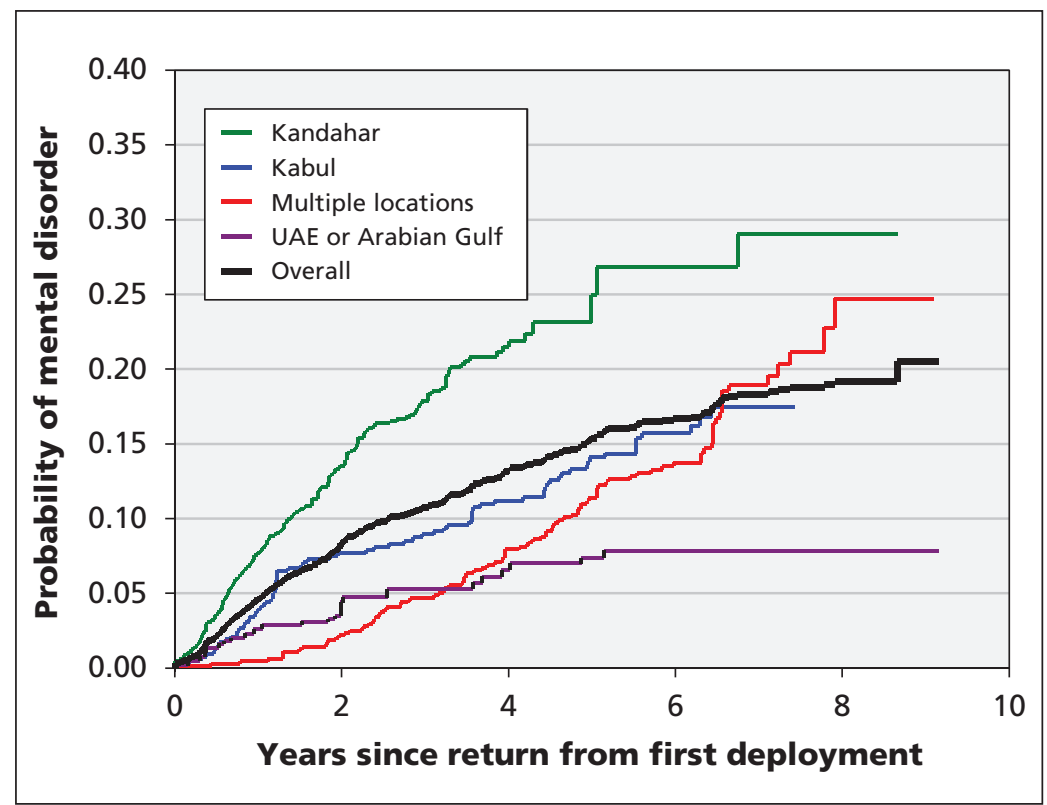

Figure 1: Kaplan-Meier estimates of the probability of a mental disorder attributed to the Afghanistan mission being diagnosed since return from the first deployment, by deployment location. United Arab Emirates (UAE) and Arabian Gulf locations were combined for ease of interpretation because there was no significant difference in incidence density or hazard ratios for these locations in the univariable analyses. vey's anonymous nature may have influenced results. ${ }^{28}$

The extensive survey data reported by other countries raise the same and other comparability issues. ${ }^{29}$ Data from historical conflicts raise even larger issues, ${ }^{6}$ including changes in the conceptualization of trauma-related disorders. ${ }^{30}$ Studies that have used administrative data on mental health care encounters are more comparable: Hoge and colleagues ${ }^{2}$ found that $9 \%-12 \%$ of US Army personnel returning from Iraq had a mental disorder diagnosed within about a year after their return; the proportion related to the most recent deployment was unknown.

Although methodologic differences preclude direct comparisons, the findings from current and past conflicts do cohere. ${ }^{29}$ For example, military personnel exposed to heavy combat have higher rates of PTSD or other mental disorders than personnel in lower-threat locations, prevalence estimates of symptoms are higher than those of clinical diagnoses, and less specific screening instruments result in higher rates of symptoms.

Others have noted the high proportion of personnel who sought care after returning from deployment $t^{31}$ and the predominance of PTSD and depression as the primary service-related mental disorders. ${ }^{32}$ Others have also noted the higher rates of mental disorders among Army personnel and those of lower rank. ${ }^{33}$ Although concerns have been raised about an increased risk of deployment-related mental health problems among women ${ }^{34}$ reservists, ${ }^{35}$ personnel with multiple deployments ${ }^{36}$ and those with more prolonged deployments, ${ }^{37}$ we found no such associations. Our finding of a strong association with deployment location mirrors data on the health effects of different deployments: for example, no association between deployment and mental disorders was seen for US peacekeeping deployments to the Middle East, Bosnia or Kosovo in the $1990 \mathrm{~s},{ }^{33}$ whereas a strong association was seen for the current conflicts in Southwest Asia. ${ }^{3,38}$

Much of the association between an Afghanistan deployment-related mental disorder and lower rank, Army service and deployment location was likely mediated by combat exposure, which is known to be a strong, consistent and independent predictor of postdeployment mental disorders. ${ }^{6}$ However, there was a meaningful incidence of mental disorders related to the Afghanistan mission among personnel who had not had any combat exposure (e.g., those stationed in the United Arab Emirates).

\section{Strengths and limitations}

The strengths of this study include its reflection of the full range of personnel deployed in sup- 
port of the Afghanistan mission; the prolonged follow-up period; the use of rigorous diagnostic assessments by clinicians experienced in the assessment of trauma-related disorders; the ability to attribute diagnoses directly to the Afghanistan-related deployment; and the use of survival analysis as the analytical approach.

The most important limitation of this research is that it captured only diagnoses made by the Canadian Forces mental health services during the follow-up period. We could not identify personnel who had mental disorders that resolved without care; those who were seen only in primary care or outside of the Canadian Forces; those who had not yet fallen ill ${ }^{39}$ or had not yet sought care; and those who sought care only after release from the Canadian Forces.

Errors in diagnosis were possible. However, the lengthy, standardized and collaborative nature of the assessment and the extensive experience of Canadian Forces clinicians with service-related mental disorders argue against that as a major source of bias. The potential for errors on the part of the clinician in attributing diagnoses to Afghanistan-related deployments are harder to dismiss. The Canadian Forces does not have a standardized approach to determine the association with deployment. In addition, clinicians may have erred on the side of attributing the diagnosis to the deployment out of a desire to assist the patient in qualifying for later benefits. These same limitations are inherent in all research relying on clinical data. Other mechanisms (e.g., population-based surveys) will be required to better understand the impact of the Afghanistan mission and to situate it in the context of mental disorders writ large in the entire Canadian Forces ${ }^{40}$ Finally, our failure to assess physical health problems in the cohort makes it impossible to place mental health into a larger health context.

\section{Conclusion}

An important minority of Canadian Forces personnel received a diagnosis of a mental disorder related to deployment in support of the Afghanistan mission. Deployment to higher-threat locations, service in the Canadian Army and lower rank were independent risk factors. This study provided a precise and methodologically rigorous estimate of the impact of the Afghanistan mission on the risk of mental disorders during continued military service. These findings will have implications in terms of service delivery and veterans' benefits. Future research with this cohort will explore the process and outcomes of the mental health care delivered to personnel with mental disorders related to the Afghanistan mission.
Table 5: Association between demographic and military characteristics and mental disorders attributed to deployment in support of the Afghanistan mission

\begin{tabular}{|c|c|c|}
\hline Characteristic & Crude HR $(95 \% \mathrm{Cl})$ & $\begin{array}{c}\text { Adjusted HR } \\
(95 \% \mathrm{Cl}) \text { from } \\
\text { selected model* }\end{array}$ \\
\hline \multicolumn{3}{|l|}{ Sex } \\
\hline Male & 1.00 (ref) & 1.00 (ref) \\
\hline Female & $1.23(0.87-1.74)$ & $1.35(0.96-1.91)$ \\
\hline \multicolumn{3}{|l|}{ Age, yr } \\
\hline$<30$ & $1.46(1.03-2.06)$ & - \\
\hline 30-39 & $1.11(0.79-1.56)$ & - \\
\hline$\geq 40$ & 1.00 (ref) & - \\
\hline \multicolumn{3}{|l|}{ Component } \\
\hline Regular Forces & 1.00 (ref) & - \\
\hline Reserve Forces & $1.15(0.69-1.90)$ & - \\
\hline \multicolumn{3}{|l|}{ Element } \\
\hline Land & 1.00 (ref) & 1.00 (ref) \\
\hline Sea & $0.47(0.29-0.75)$ & $0.92(0.54-1.57)$ \\
\hline Air & $0.38(0.26-0.55)$ & $0.60(0.40-0.87)$ \\
\hline \multicolumn{3}{|l|}{ Rank } \\
\hline Officer & $0.59(0.39-0.90)$ & $0.60(0.40-0.92)$ \\
\hline Senior NCM & $0.88(0.64-1.21)$ & $0.89(0.64-1.22)$ \\
\hline Junior NCM & 1.00 (ref) & 1.00 (ref) \\
\hline \multicolumn{3}{|l|}{ Deployment location } \\
\hline Kandahar & 1.00 (ref) & 1.00 (ref) \\
\hline Kabul & $0.48(0.35-0.66)$ & $0.48(0.35-0.66)$ \\
\hline United Arab Emirates & $0.15(0.07-0.30)$ & $0.18(0.08-0.38)$ \\
\hline Arabian Gulf & $0.25(0.14-0.46)$ & $0.23(0.11-0.48)$ \\
\hline Multiple locationst & $0.46(0.35-0.59)$ & $0.49(0.33-0.72)$ \\
\hline Unspecified & $0.36(0.23-0.56)$ & $0.33(0.21-0.52)$ \\
\hline \multicolumn{3}{|l|}{ No. of deployments } \\
\hline 1 & 1.00 (ref) & 1.00 (ref) \\
\hline 2 & $1.02(0.78-1.33)$ & $1.16(0.77-1.72)$ \\
\hline$\geq 3$ & $0.58(0.35-0.98)$ & $0.74(0.40-1.37)$ \\
\hline \multicolumn{3}{|l|}{$\begin{array}{l}\text { Duration of first } \\
\text { deployment, } d\end{array}$} \\
\hline$<180$ & 1.00 (ref) & - \\
\hline $180-365$ & $1.26(0.99-1.61)$ & - \\
\hline$>365$ & $0.51(0.12-2.18)$ & - \\
\hline \multicolumn{3}{|l|}{$\begin{array}{l}\text { Total duration of all } \\
\text { deployments, d }\end{array}$} \\
\hline$<180$ & 1.00 (ref) & 1.00 (ref) \\
\hline $180-365$ & $1.25(0.96-1.61)$ & $0.82(0.62-1.06)$ \\
\hline$>365$ & $0.92(0.63-1.34)$ & $0.66(0.41-1.07)$ \\
\hline \multicolumn{3}{|c|}{$\begin{array}{l}\text { Note: } \mathrm{Cl}=\text { confidence interval, deployment = deployment in support of the Afghanistan } \\
\text { mission, } \mathrm{HR}=\text { hazard ratio, NCM = noncommissioned officer, ref = reference group. } \\
\text { *Selected model included the variables sex, element, rank, deployment location, number of } \\
\text { deployments and total duration of deployments. } \\
\text { tThe hazard function for the "multiple locations" category represented a blending of the } \\
\text { hazards for other locations and appears to be nonproportional to the hazard function for } \\
\text { the Kandahar location at later time points; as such, care is warranted when comparing these } \\
2 \text { deployment location categories. }\end{array}$} \\
\hline
\end{tabular}




\section{References}

1. Hoge CW, Castro CA, Messer SC, et al. Combat duty in Iraq and Afghanistan, mental health problems, and barriers to care. N Engl J Med 2004;351:13-22.

2. Hoge CW, Auchterlonie JL, Milliken CS. Mental health problems, use of mental health services, and attrition from military service after returning from deployment to Iraq or Afghanistan. JAMA 2006;295:1023-32.

3. Wells TS, Leardmann CA, Fortuna SO, et al. A prospective study of depression following combat deployment in support of the wars in Iraq and Afghanistan. Am J Public Health 2010;100:90-9.

4. Smith TC, Ryan MA, Wingard DL, et al. New onset and persistent symptoms of post-traumatic stress disorder self reported after deployment and combat exposures: prospective population based US military cohort study. BMJ 2008;336:366-71.

5. Fear NT, Jones M, Murphy D, et al. What are the consequences of deployment to Iraq and Afghanistan on the mental health of the UK armed forces? A cohort study. Lancet 2010;375:1783-97.

6. Wells TS, Miller SC, Adler AB, et al. Mental health impact of the Iraq and Afghanistan conflicts: a review of US research, service provision, and programmatic responses. Int Rev Psychiatry 2011; 23:144-52.

7. Cohen BE, Gima K, Bertenthal D, et al. Mental health diagnoses and utilization of VA non-mental health medical services among returning Iraq and Afghanistan veterans. J Gen Intern Med 2010; 25:18-24.

8. Rost K, Smith JL, Dickinson M. The effect of improving primary care depression management on employee absenteeism and productivity. A randomized trial. Med Care 2004;42:1202-10.

9. Wang JL. Perceived work stress, imbalance between work and family/personal lives, and mental disorders. Soc Psychiatry Psychiatr Epidemiol 2006;41:541-8.

10. Final report: Mental Health Advisory Team (MHAT) IV: Operation Iraqi Freedom 05-07. Washington (DC): Office of the Surgeon General; 2006.

11. Armed Forces Health Surveillance Center. Hospitalizations among members of the active component, U.S. Armed Forces, 2009. Medical Surveillance Monthly Rep 2010;17:3-9.

12. Armed Forces Health Surveillance Center. Ambulatory visits among members of the active component, U.S. Armed Forces, 2009. Medical Surveillance Monthly Rep 2010;17:10-5.

13. Armed Forces Health Surveillance Center. Absolute and relative morbidity burdens attributable to various illnesses and injuries, U.S. Armed Forces, 2009. Medical Surveillance Monthly Rep 2010; $17: 16-21$.

14. Levy BS, Sidel VW. Health effects of combat: a life-course perspective. Annu Rev Public Health 2009;30:123-36.

15. Zamorski MA. Report on the findings of the enhanced post deployment screening of those returning from Op ARCHER/Task Force Afghanistan as of 11 February 2011. Ottawa (ON): Department of National Defence; 2011.

16. Boulos D, Zamorski MA. Cumulative incidence of operational stress injuries in Canadian Forces personnel deployed in support of the mission in Afghanistan, 2001-2008. Ottawa (ON): Department of National Defence; 2011.

17. Cochran WG. Sampling techniques. 3rd ed. New York (NY): John Wiley and Sons; 1977.

18. Diagnostic and statistical manual of mental disorders. Fourth edition. Text revision. Washington (DC): American Psychiatric Association; 2000.

19. Wolter KM. Introduction to variance estimation. New York (NY): Springer-Verlag; 1985.

20. Efron B. Nonparametric estimates of standard error: the Jackknife, the Bootstrap and other methods. Biometrika 1981;68:589-99.

21. Cassell DL. Bootstrap mania!: re-sampling the SAS way [paper no. 268-2010]. In: Proceedings of the SAS Global Forum 2010 Conference. Cary (NC): SAS Institute Inc.

22. Miller RG. Simultaneous statistical inference. New York (NY): Springer-Verlag; 1981.

23. Klein JP, Moeschberger ML. Survival analysis: techniques for censored and truncated data. New York (NY): Springer-Verlag; 1997.

24. Canadian Community Health Survey cycle 1.2: mental health and well-being - Canadian Forces: master file documentation. Ottawa (ON): Statistics Canada; 2004.

25. Zamorski MA, Uppal S, Boddam R, et al. The prevalence of mental health problems in the Canadian armed forces: comparison with the Canadian general population [poster]. Canadian Psychiatric Association annual meeting; 2006 Nov. 19-12; Toronto, Ont

26. 2008/2009 health and lifestyle information survey: Regular Forces report. Ottawa (ON): Department of National Defence; 2010.

27. Bliese PD, Wright KM, Adler AB, et al. Validating the primary care posttraumatic stress disorder screen and the posttraumatic stress disorder checklist with soldiers returning from combat. $J$ Consult Clin Psychol 2008;76:272-81.

28. McLay RN, Deal WE, Murphy JA, et al. On-the-record screenings versus anonymous surveys in reporting PTSD. Am J Psychiatry 2008;165:775-6.

29. Richardson LK, Frueh BC, Acierno R. Prevalence estimates of combat-related post-traumatic stress disorder: critical review. Aust N Z J Psychiatry 2010;44:4-19.

30. Dohrenwend BP, Turner JB, Turse NA, et al. The psychological risks of Vietnam for U.S. veterans: a revisit with new data and methods. Science 2006;313:979-82.

31. Milliken CS, Auchterlonie JL, Hoge CW. Longitudinal assessment of mental health problems among active and reserve component soldiers returning from the Iraq war. JAMA 2007;298:2141-8.

32. Seal KH, Metzler TJ, Gima KS, et al. Trends and risk factors for mental health diagnoses among Iraq and Afghanistan veteran using Department of Veterans Affairs health care, 2002-2008. Am J Public Health 2009;99:1651-8.

33. Riddle JR, Smith TC, Smith B, et al. Millennium Cohort: the 2001-2003 baseline prevalence of mental disorders in the U.S. military. J Clin Epidemiol 2007;60:192-201.

34. Bean-Mayberry B, Yano EM, Washington DL, et al. Systematic review of women veterans' health: update on successes and gaps. Womens Health Issues 2011;21(Suppl):S84-97.

35. Griffith J. Decades of transition for the US reserves: changing demands on reserve identity and mental well-being. Int Rev Psychiatry 2011;23:181-91.

36. Reger MA, Gahm GA, Swanson RD, et al. Association between number of deployments to Iraq and mental health screening outcomes in US Army soldiers. J Clin Psychiatry 2009;70:1266-72.

37. Buckman JE, Sundin J, Greene T, et al. The impact of deployment length on the health and well-being of military personnel: a systematic review of the literature. Occup Environ Med 2011; 68:69-76.

38. Smith TC, Ryan MA, Wingard DL, et al. New onset and persistent symptoms of post-traumatic stress disorder self reported after deployment and combat exposures: prospective population based US military cohort study. BMJ 2008;336:366-71.

39. Andrews B, Brewin CR, Philpott R, et al. Delayed-onset posttraumatic stress disorder: a systematic review of the evidence. Am J Psychiatry 2007; 164:1319-26.

40. Afifi TO, Enns MW, Cox BJ, et al. Population attributable fractions of psychiatric disorders and suicide ideation and attempts associated with adverse childhood experiences. Am J Public Health 2008;98:946-52.

Affiliation: Directorate of Mental Health, Canadian Forces Health Services Group Headquarters, Ottawa, Ont.

Funding: Funding was provided by the Canadian Forces Surgeon General's Medical Research Program. The investigators developed the study protocol, which was accepted by the study sponsor without modification. The sponsor had no direct role in the collection or analysis of the data. The sponsor did provide contextual information that assisted in the interpretation of the results. In accordance with Department of National Defence policy, the manuscript was reviewed and approved for submission without modification by the Canadian Forces Deputy Surgeon General. The authors can however attest that no undue influence on the part of the Department of National Defence, the Canadian Forces or the Government of Canada occurred at any part of this research project.

Contributors: Both authors contributed substantially to the design and implementation of the study. David Boulos managed the acquisition and collection of data and conducted the statistical analyses. Both authors contributed to the interpretation of the results and the writing and revising of the manuscript, and approved the final version of the manuscript submitted for publication.

Disclaimer: Opinions expressed or implied in this publication are those of the authors and do not represent the views or policy of the Department of National Defence or the Canadian Forces. 